\title{
humanidades
}

Revista humanidades

Diciembre, $2014 \cdot$ Volumen $4 \cdot \operatorname{ISSN} 2215-3934 \cdot$ pp. 1-17

\section{Le Déjeuner sur l'Herbe del Jardín de las Delicias (art is a private joke): Una propuesta metodológica para una crítica al exceso interpretativo}

DOI: http://dx.doi.org/10.15517/h.v4i1.16317

Recibido: 10-Febrero-2014 / Aceptado: 31-Febrero-2014

\section{Gustavo Kortsarz}

Licenciado, profesor de la Escuela Nacional de Bellas Artes "Lola Mora" y de la Escuela de Cerámica "Fernando Arranz" en Buenos Aires, Argentina.

Correo electrónico: gudako@ hotmail.com

Más sobre el autor: 


\section{Le Déjeuner sur l'Herbe del Jardín de las Delicias (art is a private joke): Una propuesta metodológica para una crítica al exceso interpretativo}

\section{Resumen}

El arte contemporáneo necesita explicación, esta necesidad se ha convertido en moda y la moda en exceso, de manera tal que encontramos textos que resultan extremadamente difíciles de vincular a las obras a las cuales se refieren, como si se tratara de un gesto independiente. Por otro lado, y en el extremo opuesto, encontramos textos que no hacen más que contarnos lo que vemos, de manera totalmente tautológica y redundante. «Le Déjeuner sur l'Herbe del Jardín de las Delicias (art is a private joke) », a manera de análisis de obra, es un comentario sobre estos excesos. El ejercicio consiste en utilizar el método clásico de análisis de obra, partiendo de los elementos plásticos y apoyándose en un punto de vista personal. Teniendo en cuenta que las interpretaciones variarán según el ángulo desde donde se enfoque el análisis, la propuesta consiste en una demostración por el método del absurdo a través de una argumentación con bases sólidas.

\section{Le Déjeuner sur l'Herbe del Jardín de las Delicias (art is a private joke): A methodological critique of interpretive excess}

\footnotetext{
Abstract

Contemporary art calls for explanation and this requirement is much in vogue today, to the point of excess. On the one hand, there are some interpretations where it is extremely difficult to find the connection between the text and the work of art it is referring to. On the other hand, there are texts that do nothing more than tell us what we see in a tautalogical and redundant manner. As an analysis of a work of art, "Le Déjeuner sur l'Herbe del Jardín de las Delicias (art is a private joke)" is a comment on these excesses. Starting from visual elements and a personal point of view, the exercise consists of utilizing a classical method of analysis of a work of art. The interpretations will vary according to the angle from which the analysis is approached; accordingly, a demonstration by reductio ad absurdum through a solid argumentation is proposed.
} Keywords: Manet, Genesis, Eva, Lilith, analysis of works of art.

Palabras clave: Manet, Génesis, Eva, Lilith, análisis de obra. 
Podríamos imaginar la historia de la siguiente manera: Se trata de un fin de semana agradable y soleado, y dos parejas de enamorados hacen un plácido paseo en bote por el Sena. En una de sus vueltas el río pasa cerca de un pequeño bosque y los paseantes deciden detenerse allí para hacer un picnic a la sombra de los árboles; las mujeres aprovechan la oportunidad para meterse en el agua, después de lo cual una de ellas, desnuda, espera que la tibia brisa le seque la piel, mientras que los hombres conversan. Puede ser que las mujeres traten en vano de seducir a los hombres que no se dejan distraer, inmersos en un intercambio de información sobre la próxima carrera de caballos en el hipódromo de Auteuil. Una de las mujeres, ofendida ante la indiferencia masculina, se dirige a nosotros, espectadores de la escena, en busca de consuelo.

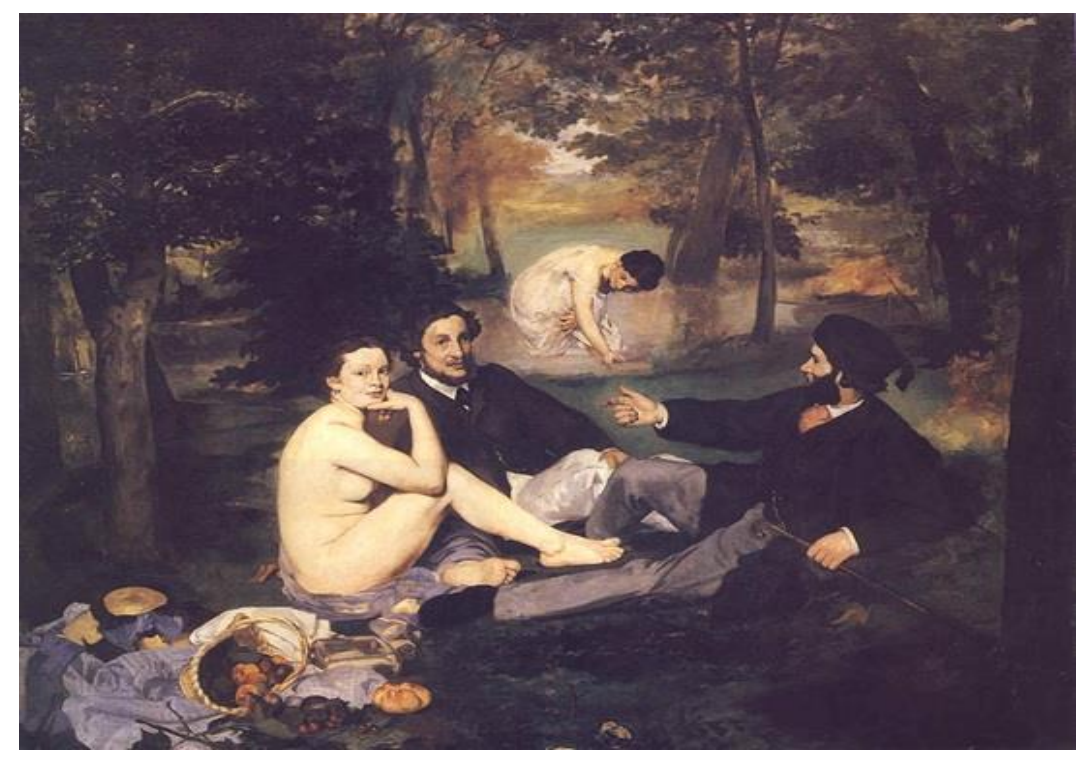

Édouard Manet, Le Déjeuner sur l'Herbe (1863). Óleo sobre lienzo, 208 cm x 264,5 cm. Musée d'Orsay, París. 
De todos modos, la situación es bastante extraña. Los dos hombres están completamente vestidos y la mujer en el agua aún mantiene alguna de sus ropas, mientras que la mujer en primer plano parece no tener frío a pesar de su desnudez.

Antonin Proust, amigo del pintor, escribe:

En las vísperas del día en que hizo el Déjeuner sur l'herbe y Olympia, estábamos un domingo en Argenteuil, tendidos a orillas del río [...]. Algunas mujeres se bañaban. Manet tenía la mirada fija en la piel de las mujeres que salían del agua. Pareciera -dijo- que tenga que hacer un desnudo. Bueno, les voy a hacer uno. Cuando estábamos en el taller, copié las mujeres de Giorgione, las mujeres con los músicos. Está muy oscuro ese cuadro. El fondo ha vuelto a la superficie de la tela. Quiero hacer esto de nuevo pero hacerlo en una atmósfera transparente, con personajes como los que vemos allí. Me van a demoler. Van a decir que me inspiro de los italianos después de haberme inspirado en los españoles (Proust, 1996). 


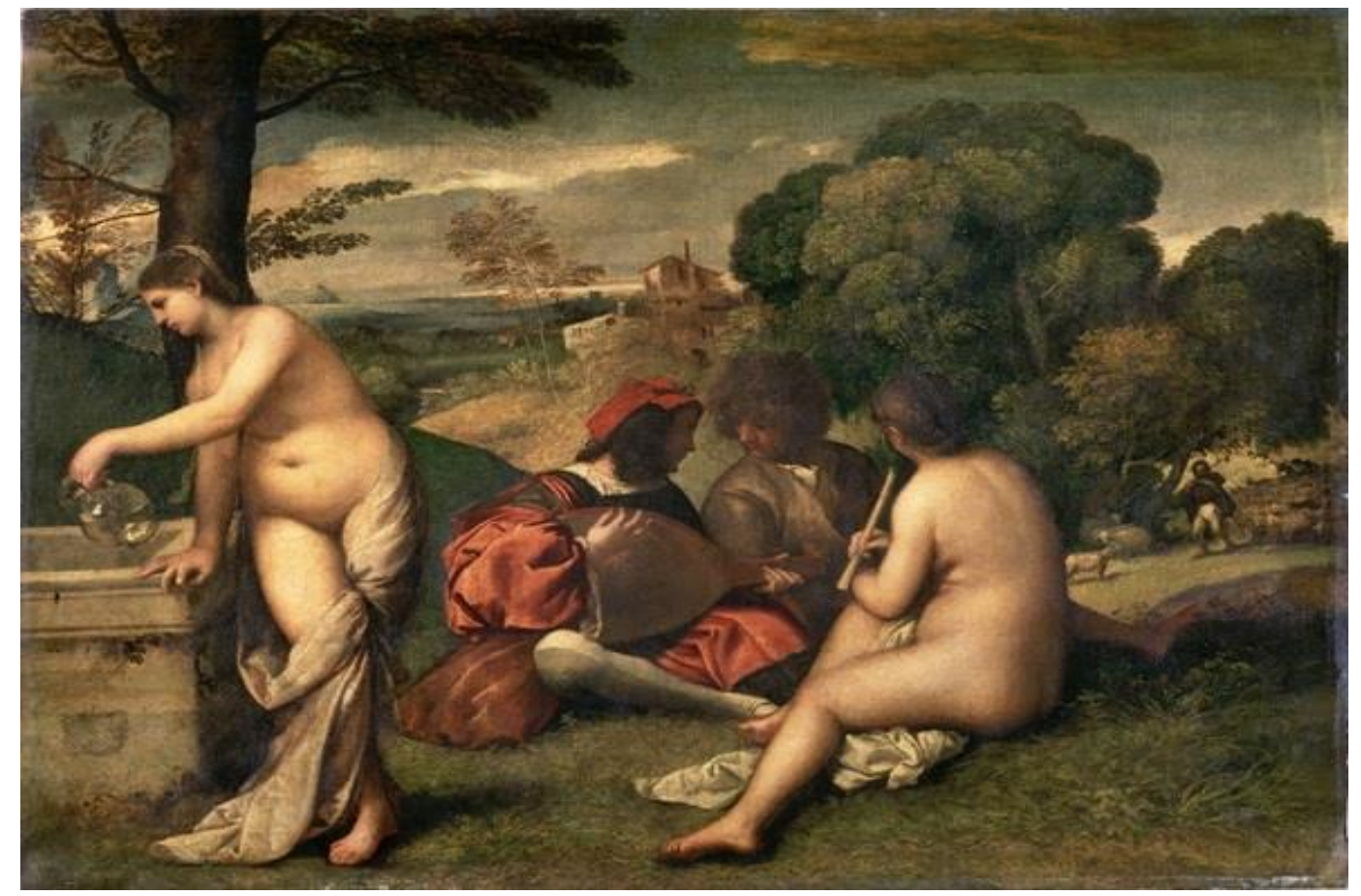

Tiziano Vecellio, Concierto Campestre (1509). Óleo sobre lienzo, $105 \mathrm{~cm}$ x $137 \mathrm{~cm}$. Musée du Louvre, París.

Según Antonin Proust se trataría casi de un desafío: Pareciera que tenga que hacer un desnudo. Bueno, les voy a hacer uno... y, tal como lo transcribe en el texto citado arriba, Manet encuentra su inspiración, por un lado, en el Concierto campestre, pintura atribuida, en aquel entonces, a Giorgione. Se trata de una escena de exterior donde podemos ver en primer plano, al centro 
de la imagen, dos hombres jóvenes vestidos que se miran atentamente mientras uno de ellos parece tocar la mandolina, sin hacer caso a la presencia de dos figuras femeninas desnudas que se encuentran a su lado; una de las cuales, sentada en frente de ellos, con flauta en mano, toma parte en el concierto, mientras que la otra, a la izquierda, de pie, saca agua de un pozo. Manet toma, entonces, la idea de dos hombres vestidos y dos mujeres desnudas, así como la ubicación de tres personajes sentados y una mujer de pie.

Otra fuente del cuadro es el Juicio de Paris, composición en la que aparece un gran número de figuras desnudas, dispuestas en grupos, entre los cuales hay un conjunto situado en el extremo derecho, con dos hombres y una mujer en actitudes casi idénticas a las del Déjeuner sur l'herbe. 


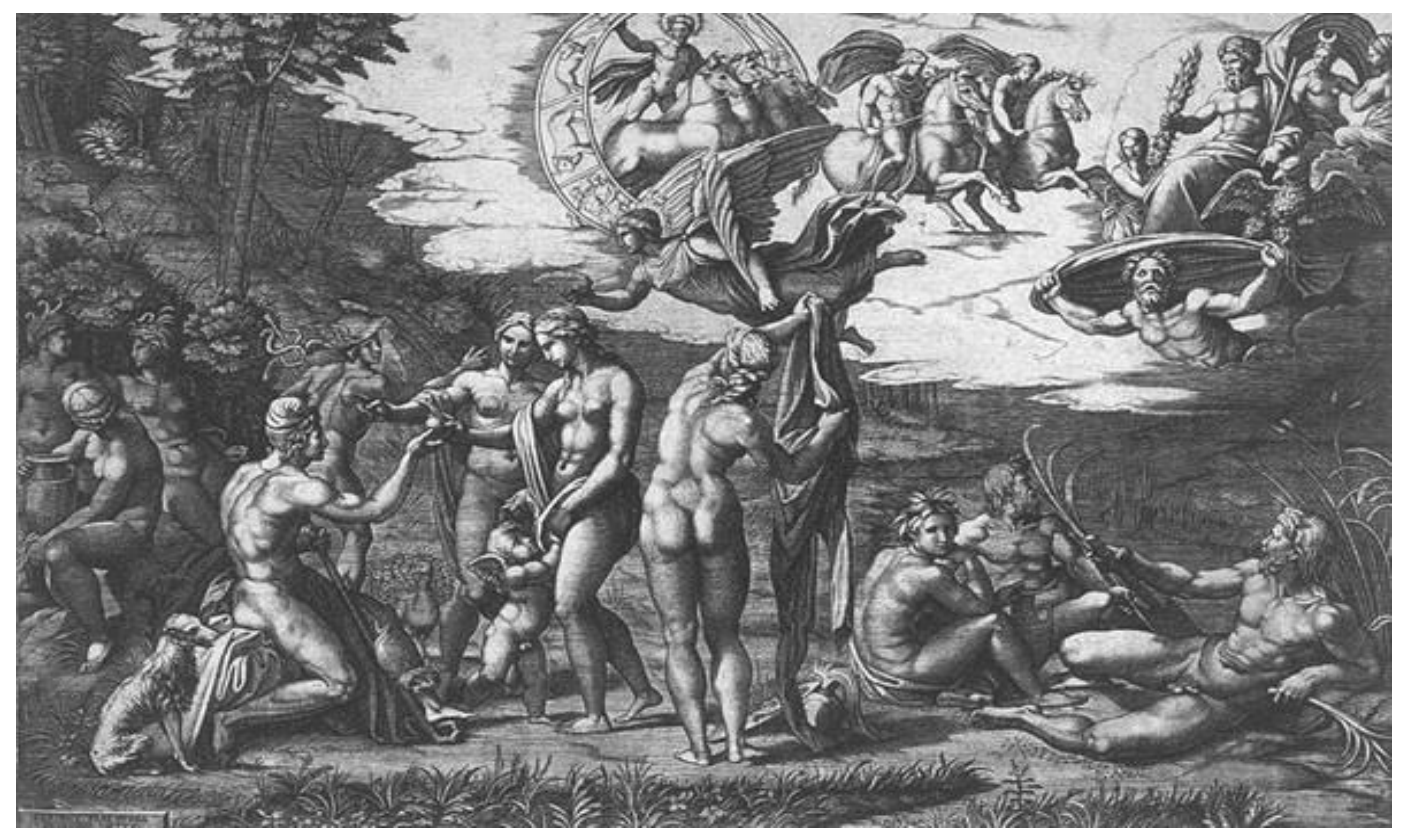

Marcantonio Raimondi, El juicio de Paris (1515). Grabado, buril, 29,4 cm x 43,8 cm. Musé du Louvre, París.

La pintura causó un escándalo y Zola salió en defensa del pintor:

[...] El Déjeuner sur l'herbe es la pintura más importante de Edouard Manet, aquella en la cual hizo realidad el sueño de todos los pintores: poner figuras de tamaño natural en un paisaje. Sabemos con qué potencia ha superado esta dificultad. Podemos ver allí algunos árboles, hojas, troncos, y, al fondo, un río en el cual se baña una mujer en camisa; en el primer plano, dos hombres jóvenes están sentados frente a una segunda mujer que acaba de salir del agua y seca su piel desnuda al aire libre. Esta mujer desnuda 
ha escandalizado al público, que no ha visto otra cosa más que ella ¡Dios mío, qué indecencia: una mujer sin el más mínimo velo entre dos hombres vestidos! Esto nunca se había visto. Y esta creencia es un grosero error, ya que hay en el Museo del Louvre más de cincuenta cuadros en los que se mezclan personajes vestidos y desnudos. Pero a nadie se le ocurriría escandalizarse en el Louvre. La multitud se cuidó muy bien de juzgar el Déjeuner sur l'herbe tal como debe ser juzgada una verdadera obra de arte, sólo se limitó a ver unas personas que comían en el bosque, al salir del baño, y creyó que el artista había puesto una intención obscena y provocadora en la elección del tema, cuando lo que había buscado era simplemente tratar de obtener fuertes contrastes y amplias masas de color. Los pintores, y especialmente Édouard Manet, que es un pintor analista, no tienen esa preocupación por el tema que tanto atormenta al público, el tema es para ellos sólo un pretexto para pintar, mientras que para el público lo único importante es la anécdota. Es así que, sin duda, la mujer desnuda del Déjeuner sur l'herbe no es más que una excusa que le ofrece al artista la oportunidad de pintar un poco de piel. Lo que hay que ver en el cuadro no es un almuerzo campestre, sino el paisaje en su totalidad, con su fuerza y su delicadeza, con sus amplios primeros planos, tan sólidos, y sus fondos suaves y delicados; es esta carne firme, modelada con grandes planos de luz, sus telas blandas y fuertes, y en particular, esta deliciosa silueta de mujer en camisa que constituye, en el fondo, una adorable mancha blanca en medio de las hojas de color verde; este vasto conjunto, pleno de aire, este rincón de 
la naturaleza hecho con tal precisa sencillez, esta admirable página en la que un artista ha puesto todos los elementos particulares que estaban en él [...] (Zola, 1867).

Según este escritor, no habría ninguna razón de conmoverse, el tema sería solo una excusa, un soporte para la pintura, única y verdadera protagonista del cuadro. Por supuesto, si aún hoy hablamos de esta obra es que Zola tiene una parte de razón, ya que si la pintura hubiese sido, en términos plásticos, sin interés, la controversia sobre esta ya estaría cerrada. Pero a pesar de que Zola quiera terminar, de una vez por todas, con la discusión acerca del tema, este existe y su importancia no es menor.

De todos modos, el Déjeuner sur l'herbe nunca había despertado mi curiosidad, hasta el día en que, de espera en una sala donde habían instalado en una pared una reproducción enorme, mucho más grande que el original, de la pintura de Manet, mi mirada se dejara llevar. Al principio mi interés estuvo centrado en la composición, luego pasó al espacio, y finalmente a la anécdota, y había allí un detalle que me intrigaba.

En cuanto a la organización del espacio, nos encontramos frente a una escena, y esto en el sentido teatral de la palabra. Pareciera que los personajes se encontrasen delante de un telón. Un espacio poco profundo en el cual el último plano parece una tela pintada colocada detrás de los protagonistas de la acción. 
El cuadro fue, por supuesto, realizado en el taller de Manet, no se trata de una pintura al aire libre, y el pintor ha hecho hincapié en el carácter artificial de la representación. Y, al igual que en el escenario de un teatro el escenógrafo, limitado por las dimensiones de la escena, se vale de trucos para acentuar la sensación de profundidad. Manet se vale de trucos en el cuadro, no para aumentar dicha sensación sino para trastocarla.

La perspectiva ha sido forzada, dando al espacio un aspecto rebatido que nos anticipa a Gauguin. El punto de vista desde el que se representa a la Venus, frontal, es diferente al utilizado para los otros elementos del cuadro, más alto y ligeramente en picado. Las dimensiones relativas de la bañista en último plano y del bote situado detrás de ella contribuyen a crear una sensación espacial ambigua, ya que el bote debería ser más grande, solo basta con compararlo con el tronco del árbol en la otra orilla que, en comparación al bote es enorme, tomando las proporciones de una secuoya gigante.

Ese mundo teatral, artificial, irreal, es el Paraíso en el momento de la creación, el río en el centro del cuadro constituye un punto de referencia que nos sitúa geográficamente en el Jardín de las Delicias:

De Edén salía un río que regaba el jardín, y desde allí se repartía en cuatro brazos (Génesis 2:10, La Biblia). 
La mano extendida del hombre, situado a la derecha, se parece a la de Dios creando a Adán en la versión de Miguel Ángel, en una etapa del movimiento estrechamente ligada a la imagen de la Capilla Sixtina.
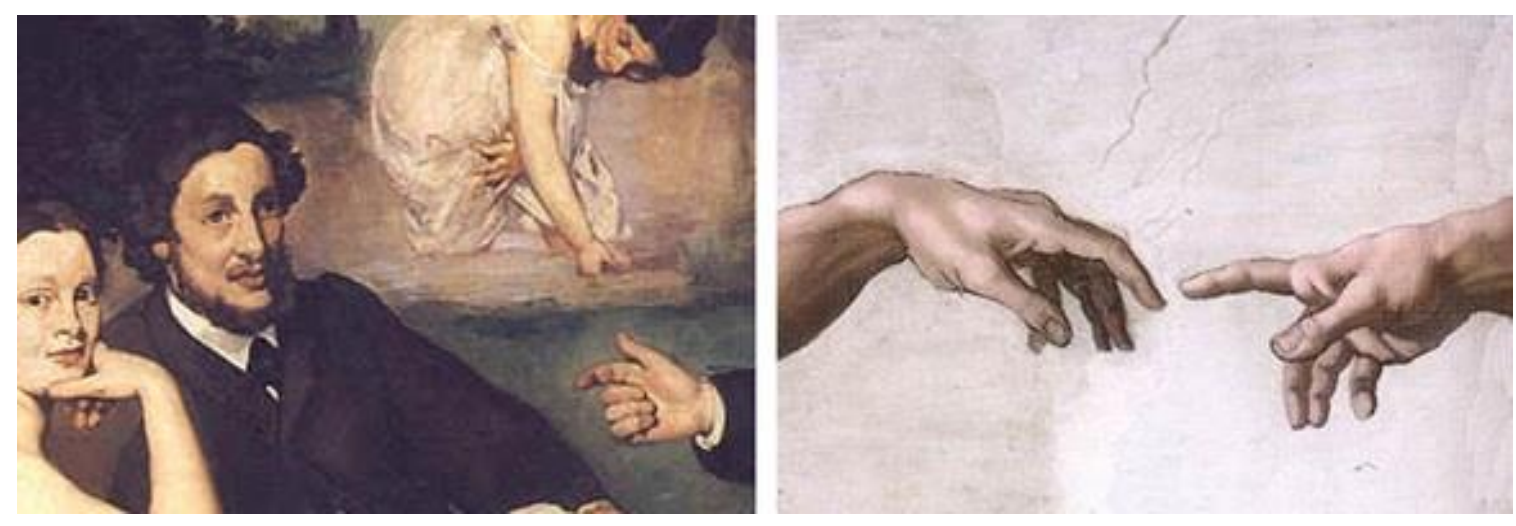

Izq. : Le Déjeuner sur l'Herbe (detalle). Der. : Michelángelo Buonarotti. Detalle de La Creación de Adán (1511). Fresco, $480 \mathrm{~cm}$ x $230 \mathrm{~cm}$. Capilla Sixtina, Vaticano.

Vamos a focalizarnos en esta mano, que se separa del fondo gracias a los tonos claros de los verdes que la rodean; es como un halo luminoso alrededor de ella, halo que nos envía, una vez más, hacia una "santidad" del acto. Uno de los dedos de esta mano pintada por Manet, el pulgar, dirigido hacia arriba, nos conduce a la mujer en el agua, mientras que el índice, ligeramente flexionado, nos lleva a la mujer en primer plano, la misma que con el pie señala la entrepierna del "Creador". Nuestro Adán, el del Déjeuner sur l'herbe, parece perdido en sus pensamientos, mientras que 
ella, en su magnífica desnudez, está más interesada en nosotros, espectadores, que en la conversación con los personajes del cuadro, constituyéndose así un verdadero vínculo entre el espacio interior y exterior de la tela.

En el relato bíblico del Génesis hay dos momentos en los que se habla de la creación del hombre. Es así que, en el primero de ellos nos dice que Dios creó al hombre y a la mujer al mismo tiempo y a su semejanza: Dijo Dios: «Hagamos al hombre a nuestra imagen y semejanza. Que tenga autoridad sobre los peces del mar y sobre las aves del cielo, sobre los animales del campo, las fieras salvajes y los reptiles que se arrastran por el suelo»

Y creó Dios al hombre a su imagen. A imagen de Dios lo creó.

Varón y mujer los creó.

Dios los bendijo, diciéndoles: «Sean fecundos y multiplíquense.

Llenen la tierra y sométanla [...]» (Génesis 1:26-28, La Biblia).

Unos párrafos más adelante se habla de nuevo de la creación del hombre y se dice que Dios creó a Adán del barro y, más tarde, y para que no estuviese solo, de uno de sus costados creó a la mujer: 
Entonces Yahveh Dios formó al hombre con polvo del suelo, e insufló en sus narices aliento de vida, y resultó el hombre un ser viviente (Génesis 2:7, La Biblia).

Dijo luego Yahveh Dios: «No es bueno que el hombre esté solo. Voy a hacerle una ayuda adecuada».

Y Yahveh Dios formó del suelo todos los animales del campo y todas las aves del cielo y los llevó ante el hombre para ver cómo los llamaba, y para que cada ser viviente tuviese el nombre que el hombre le diera.

El hombre puso nombres a todos los ganados, a las aves del cielo y a todos los animales del campo, mas para el hombre no encontró una ayuda adecuada.

Entonces Yahveh Dios hizo caer un profundo sueño sobre el hombre, el cual se durmió. Y le quitó una de las costillas, rellenando el vacío con carne.

De la costilla que Yahveh Dios había tomado del hombre formó una mujer y la llevó ante el hombre.

Entonces éste exclamó: «Esta vez sí que es hueso de mis huesos y carne de mi carne. Esta será llamada mujer, porque del varón ha sido tomada». 
Por eso deja el hombre a su padre y a su madre y se une a su mujer, y se hacen una sola carne (Génesis 2:18-24, La Biblia).

Este es un tema de discusión y ha sido interpretado de diferentes maneras, una de ellas considera que las dos historias son independientes y pone el acento en el hecho de que en la primera, Dios los creó a ambos, hombre y mujer, del barro, al mismo tiempo y a su semejanza, lo que las coloca en pie de igualdad, mientras que en el segundo relato Dios creó al hombre en primer lugar, del barro, y es apartir de él que hizo a la mujer, lo que la coloca en una posición de subordinación, situación que se ve reforzada por la idea de que fue creada como un remedio para la soledad de Adán. Siguiendo este camino de interpretación, Dios habría creado dos mujeres de las cuales Eva sería la segunda de ellas. De acuerdo a antiguas leyendas semitas la primera se llamaría Lilith.

Ella, Lilith, considerándose la igual de Adán, no aceptaba de ninguna manera hacer el amor siempre en la misma posición, es decir, debajo del hombre, y como él no quería cambiar absolutamente nada en sus relaciones, Lilith decidió abandonar a Adán y el Paraíso. Como Adán se quejara de su situación, Dios envió tres ángeles a fin de convencer a la mujer para que regresara junto a su hombre, pero ella se negó. Es por ello que Dios tuvo que crear otra mujer, Eva, pero esta vez no de la tierra como Adán, si no a partir del cuerpo del hombre, haciendo de ella el ser sumiso que aquel esperaba. 
Mientras observa a Adán (melancólico, absorto en sus pensamientos), de un gesto de su mano derecha el Creador nos señala con su dedo índice a la rebelde Lilith, aquella que dejará el Paraíso, mientras que con su pulgar nos dirige a Eva, su remplazante en el lecho matrimonial.

En apoyo de esta tesis, en primerísimo primer plano del cuadro, inmediatamente delante de la mujer desnuda, Manet nos muestra una naturaleza muerta constituida por ropas femeninas sobre las que se ha volcado una canasta con frutas. El vestido, que a manera de mantel nos ofrece sus frutas de verano es, evidentemente, el que Lilith se ha sacado. La cesta con frutas es una alusión directa al árbol del conocimiento del bien y del mal y el hecho de haberlo pintado en esta posición (volcado) con algunas frutas diseminadas, evidencia que Lilith ya las había probado, y esto, antes de la prohibición divina, razón por la cual es el único personaje desnudo del cuadro. Y es que sería a partir de esta experiencia que el Creador habría determinado la prohibición, con las consecuencias vestimentarias por todos conocidas.

En Génesis 1, Dios creó al hombre y a la mujer juntos e inmediatamente después les ofrece todos los frutos como alimento y sin prohibición alguna:

Dijo Dios: «Ved que os he dado toda hierba de semilla que existe sobre la faz de toda la tierra, así como todo árbol que lleva fruto de semilla; para vosotros será de alimento (Génesis: 1:29, La Biblia). 
Sin embargo, en Génesis 2, Dios creó primero al hombre, luego le dice que puede comer de todo excepto el fruto del árbol del conocimiento del bien y del mal, y esta prohibición es pronunciada antes de la creación de la mujer:

Y Dios impuso al hombre este mandamiento: «De cualquier árbol del jardín puedes comer, mas del árbol de la ciencia del bien y del mal no comerás, porque el día que comieres de él, morirás sin remedio» (Génesis 2:16-17, La Biblia)

Lilith no es expulsada del paraíso, Lilith lo deja por su propia voluntad. Ella no quiere interpretar un rol secundario. Manet, en una composición que presenta varios momentos de una misma historia, como un moderno Masaccio, nos permite ver el momento en que todo se convulsiona. Lilith ya no quiere estar en el Paraíso, pero aún no le han crecido las alas que le permitirán volar. Ha tomado conciencia de aquello que no está dispuesta a aceptar e imagina ya otra vida posible.

El escándalo causado por el cuadro no se debe a la representación de esta mujer desnuda rodeada de hombres vestidos, sino del misterio revelado por el pintor: la perplejidad, la confusión, la problemática situación de Dios creando a la mujer. 
Le Déjeuner sur l'Herbe del Jardín de las Delicias...

Proust, Antonin (1996). Edouard Manet - souvenirs. L'Échoppe, París.

Zola, Emile (1867). Édouard Manet, étude biographique et critique. En Écrits sur l'art, Gallimard.

Referencias

bibliográficas 